\title{
Auditory Effects of Exposure to Noise and Solvents: A Comparative Study
}

\author{
Diolen Conceição Barros Lobato ${ }^{1}$ Adriana Bender Moreira De Lacerda ${ }^{2}$ \\ Cláudia Giglio De Oliveira Gonçalves ${ }^{2}$ Herton Coifman ${ }^{3}$
}

\author{
${ }^{1}$ Department of Audiology, Universidade Tuiuti do Paraná; \\ Universidade da Amazônia, Belém, PA, Brazil \\ ${ }^{2}$ Department of Comunication Disorders, Universidade Tuiuti do \\ Paraná, Curitiba, PR, Brazil \\ ${ }^{3}$ Departament of Otorhinolaryngology, Universidade Federal do \\ Paraná, Curitiba, PR, Brazil
}

Int Arch Otorhinolaryngol 2014;18:136-141.

\author{
Address for correspondence Diolen Conceição Barros Lobato, \\ Universidade Tuiuti do Paraná, Rua Engenheiro Niepce da Silva, 290, ap \\ 72E, Portão, Curitiba, Paraná, Brasil 80610-280 \\ (e-mail: dlobato.fono@hotmail.com).
}

\begin{abstract}
Keywords

- solvents

- occupational health

- audiology

- hearing loss

- noise-induced

Introduction Industry workers are exposed to different environmental risk agents that, when combined, may potentiate risks to hearing.

Objective To evaluate the effects of the combined exposure to noise and solvents on hearing in workers.

Methods A transversal retrospective cohort study was performed through documentary analysis of an industry. The sample $(n=198)$ was divided into four groups: the noise group (NG), exposed only to noise; the noise and solvents group (NSG), exposed to noise and solvents; the noise control group and noise and solvents control group (CNS), no exposure.

Results The NG showed $16.66 \%$ of cases suggestive of bilateral noise-induced hearing loss and NSG showed 5.26\%. The NG and NSG had worse thresholds than their respective control groups. Females were less susceptible to noise than males; however, when simultaneously exposed to solvents, hearing was affected in a similar way, resulting in significant differences $(p<0.05)$. The 40 - to 49 -year-old age group was significantly worse $(p<0.05)$ in the auditory thresholds in the NSG compared with the CNS.

Conclusion The results observed in this study indicate that simultaneous exposure to noise and solvents can damage the peripheral auditory system.
\end{abstract}

\section{Introduction}

The number of environmental contaminants in the workplace investigated for their ototoxic/neurotoxic properties leading to hearing loss is reduced. Three groups of contaminants are considered high priority for research to be potentially ototoxic and are present in various production processes: solvents, asphyxiants, and heavy metals, as well as today's organophosphate pesticides. ${ }^{1,2}$

In recent decades, a few studies have identified organic solvents as environmental contaminants that are more dan- gerous to health. It is known that organic solvents can act as ototoxic and neurotoxic agents, causing severe damage to hearing, especially in the presence of noise. ${ }^{2-7}$

The health effects depend on the toxicity of the solvent and are related to their physical-chemical and metabolic properties. For the worker, the pathway, exposure concentration, absorbed dose, time of exposure, susceptibility of the individual worker, toxic metabolites, medical conditions, and combination with other chemical exposures are relevant to the associated risk. Multiple exposures to solvents are a common risk in the work environment. ${ }^{7}$ received

July 27,2013

accepted

September 10, 2013
DOI http://dx.doi.org/

10.1055/s-0033-1361083. ISSN 1809-9777.
Copyright $(2014$ by Thieme Publicações License terms Ltda, Rio de Janeiro, Brazil

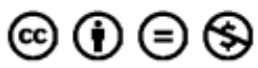


It is possible to verify that simultaneous exposure to noise and solvents has a additive toxic effect to the peripheral auditory system, confirming the harmfulness of associated agents, ${ }^{8-15}$ leaving sequelae in specific frequencies 2 to $4 \mathrm{kHz},{ }^{16}$ and significantly increasing the risk of acquiring occupational hearing loss. In this context, noise cannot be considered the only threat to workers' hearing. ${ }^{1,3,8-11}$

Other studies suggest that workers exposed to solvents are more likely to acquire central auditory disorders. The studies conclude that the exclusive use of pure tone audiometry is insufficient to assess the auditory system (peripheral and central). 6,10,17-20

Studies suggest that auditory damage (peripheral or central) is observed, ${ }^{11}$ even though the exposures to each risk agent (noise and solvents) are within the limits permitted in Regulatory Norm (NR)-15 (noise: 85 dBA (Decibel - the weighting filter $\mathrm{A}$ ) and solvents: 78 parts per million). ${ }^{16,21,22}$

The aim of this study was to evaluate the effects of simultaneous exposure to noise and solvents on hearing in workers.

\section{Materials and Method}

This is a transversal retrospective cohort study, ${ }^{23}$ approved by the Ethics Committee on Human and Animal Research under number 000183/2009, with proper signatures on consent forms.

The study was performed by documentary analysis for a metal graphics company that operates in the steel container market of paints, varnishes, and automotive fillers. The production sector operates in two brick-construction barracks, equipped with an exhaust system and a natural ventilation system and with artificial and natural lighting systems. The total area of the company is $8,384.93 \mathrm{~m}^{2}$. The company offers specialized services in safety engineering and occupational medicine and its 207 employees worked in two 8-hour shifts. The personal protective equipment, such as hearing protection, gloves, and masks, were provided and the staff signed receipts for this material.

We analyzed the following documents in the years 2009 to 2010: the Medical Control and Occupational Health Program, Program for the Prevention of Environmental Risks, Quantitative Environmental Assessment for Chemical Agents, Risk Map, and the staff's medical records, including laboratory tests and pure tone audiometry for the latest yearly exam (NR-7, NR-9, NR-15). ${ }^{24,25}$

Of the 207 workers, 108 were excluded. Inclusion criteria were: working in the production sector, absence of clinical audiological history, absence of exposure to noise or chemicals outside work, normal meatoscopy, and exposure to solvents for more than 2 years (because there are reports in the literature that the time required for hearing disorders is triggered as a result of exposure to solvents at around 2 to 3 years ${ }^{16}$ or even more than 5 years of exposure, and exposure to only noise can have side effects in the first 5 years of exposure). ${ }^{8,16}$ Inclusion criteria for the control groups were: all volunteer participants without complaints or hearing impairment, without history of ear problems, and without exposure to noise and chemicals.
Thus, the study group consisted of 198 participants, including 134 males and 64 females, distributed according to the current occupational exposure to risk agents (noise and noise plus solvents). For the formation of the noise control group (CN) and noise and solvents control group (CNS), the database of the Department of Audiology at the University was used.

The participants were distributed in four groups:

- Noise group (NG): 42 subjects exposed only to noise (standard levels of exposure equivalent to 85 to $93 \mathrm{dBA}$ )

- Noise and solvents group (NSG): 57 subjects simultaneously exposed to noise (standard levels of exposure equivalent to 88 to $98 \mathrm{dBA}$ ) and solvents (aromatic hydrocarbons, toluene, xylene, turpentine, oils, greases, lead chromates and molybdates), considered to be below the tolerances set out in NR-15 22

- CN: 42 subjects from the database of the Department of Audiology at the Universidade Tuiuti do Paraná without noise and contaminants exposure

- CNS: 57 subjects from the database of the Department of Audiology at the Universidade Tuiuti do Paraná, without noise and contaminants exposure

Because there were two different experimental groups (NG and NSG), each study group had their respective matched control group in terms of age and gender.

Due to this being a cross-sectional study, previous exposure was not controlled. We emphasize that none of these subjects presented auditory problems before starting work for the company, as the company's policy is to only hire employees with normal hearing thresholds.

The audiometric tests were classified according to the criteria of Appendix I of NR-7 (Ordinance 19) of the Ministry of Labor (1998). ${ }^{24}$ Subjects with hearing thresholds above 25 $\mathrm{dB}$ hearing loss at frequencies of 3, 4, and/or $6 \mathrm{kHz}$ and higher than other tested frequencies, whether the latter were altered or not, were considered to have hearing loss induced by highintensity sound pressure levels. ${ }^{24}$

The group characteristics and the prevalence of hearing loss were analyzed. Descriptive analyses were performed on the basis of documentary analysis. For the characterization of workers in relation to the variables of age, gender, and duration of exposure to noise and noise and solvent with the results of audiometry, descriptive methods and the Mann-Whitney test were used, and a $p$ value less than or equal to 0.05 was considered statistically significant.

\section{Results}

- Table 1 shows the characteristics of the population according to age and time of exposure to noise and solvents. Participants in the NG ranged from 22 to 65 years old (mean $=39.3$, standard deviation $=10.3$ ) and the exposure time varied from 2 to 35 years (mean $=9$, standard deviation $=6.5$ ). In the NSG, ages ranged from 22 to 60 years old (mean $=38.7$, standard deviation $=8.9$ ), and exposure time varied from 2 to 35 years (mean $=9.2$, standard deviation $=5.8$ ). 
Table 1 Descriptive statistics of the groups according to age and time of exposure to noise and solvents $(n=198)$

\begin{tabular}{|l|l|l|l|l|l|l|l|l|}
\hline \multirow{2}{*}{ Groups } & \multicolumn{4}{|c|}{ Age $(\mathrm{y})$} & \multicolumn{4}{c|}{ Time of exposure (y) } \\
\cline { 2 - 9 } & Average & SD & Minimum & Maximum & Average & SD & Minimum & Maximum \\
\hline NG & 39.3 & 10.3 & 20.0 & 65.0 & 9.0 & 6.5 & 2 & 35 \\
\hline NSG & 38.7 & 8.9 & 22.0 & 60.0 & 9.2 & 5.8 & 2 & 32 \\
\hline
\end{tabular}

Abbreviations: NG, noise group; NSG, noise and solvent group; SD, standard deviation.

Our findings demonstrate the existence of a significant positive correlation between age and duration of exposure (i. e., the higher the age, the higher the exposure time: NG, $p=0.0001$, and NSG, $p=0.0010$ ).

- Table 2 shows the results of the audiological evaluation groups, by ear, according to the classification proposed by Appendix I of NR-7 (Ordinance 19). Results showed that most participants in the subject groups, noise as well as noise and solvents, had normal hearing.

- Table 3 shows the mean thresholds of the NG, NSG, CN, and CNS as a function of gender. Significant values were observed in male workers in the NG at frequencies of $4 \mathrm{kHz}$ bilaterally and $6 \mathrm{kHz}$ in the left ear.

- Table 4 shows the comparison of hearing thresholds of NG, CN, NSG, and CNS as a function of gender. Significant values were observed in male workers in the $\mathrm{NG}$ at frequencies of 4 and $6 \mathrm{kHz}$ bilaterally and $8 \mathrm{kHz}$ in the left ear. In the NSG, significant differences were observed in both sexes for low as well as high frequencies.

- Table 5 shows the comparison of hearing thresholds of NG, CN, NSG, and CNS as a function of age. There was a statistically significant difference between the thresholds of the NSG especially in the 40 - to 49 -year age group.

\section{Discussion}

This study had a predominance of male subjects under 40 years of age and a time of exposure to risk agents of less than 9 years, which is common in most research in the occupational area, as these are developed exclusively with males working in the production phase. $2,6,8,10,11,13,19,20$

Aromatic hydrocarbons, toluene, turpentine, and xylene (mixed solvents) used in the evaluated industry are classified as ototoxic contaminants. ${ }^{3,4}$ However, the concentration at which the study's subjects are exposed, according to the Quantitative Environmental Assessment, is below the tolerances set out in NR-15 22 and American Conference of Governmental Industrial Hygienists (ACGIH). ${ }^{26}$
Research institutions such as National Institute for Occupational Safety and Health and ACGIH recommend that workers exposed to chemicals undergo audiometric testing. ${ }^{1,26}$ In Brazil, labor legislation does not recommend periodic audiometric examinations in workers exposed to ototoxic contaminants except for those exposed to noise levels above $85 \mathrm{dBA}$ for 8 hours per day. ${ }^{24}$ But Social Security Decree 3048 of May 6, 1999, recognizes some chemicals as risk factors for occupational hearing loss, suggesting that this type of exposure should be considered when evaluating the causal link between hearing loss and environment work conditions. ${ }^{27}$

The findings in - Tables $\mathbf{2}$ and $\mathbf{3}$ lead us to the hypothesis that the noise effects outweigh the effects of solvents, and audiometry alone cannot identify early hearing loss (peripheral and central) arising from exposure to noise and solvents, as suggested by some authors. ${ }^{3,5,20,21}$

When comparing male subjects exposed only to noise with controls, as shown in $\mathbf{- T a b l e ~} \mathbf{4}$, it is clear the influence of noise on hearing thresholds of participants agrees with other national studies. ${ }^{1,13}$ This effect was not seen in female participants, which leads us to think that they are less susceptible to noise than males, ${ }^{28}$ that this difference may be related to the fact that changes in hearing happen earlier in men than in women as suggested by the literature, ${ }^{29}$ or that women are more preventive than men and make better use of hearing protection. ${ }^{30}$

The same comparison was performed with the NSG and its respective controls ( - Table 4 ), and it was noted that when the solvent was present and associated with noise, both the female and the male hearing thresholds were worse compared with the controls, strengthening the influence of the simultaneous action of noise and solvents on hearing. ${ }^{14,15}$

These findings demonstrate that the effects of exposure to noise and solvents by gender manifest themselves differently to the effects of exposure to noise only and are consistent with other studies ( - Table 4). ${ }^{9}, 13,14$ This finding deserves further investigation, as most research on combined exposures of noise and environmental contaminants are developed exclusively for males. ${ }^{7,12,16,21,22}$

Table 2 Audiological assessment results, classified according to Appendix I of Regulatory Norm 7

\begin{tabular}{|c|c|c|c|c|c|c|c|c|c|c|c|c|}
\hline \multirow[t]{3}{*}{ Groups } & \multicolumn{6}{|c|}{ Right ear } & \multicolumn{6}{|c|}{ Left ear } \\
\hline & \multicolumn{2}{|c|}{ Normal } & \multicolumn{2}{|c|}{ NIHL } & \multicolumn{2}{|c|}{ Others } & \multicolumn{2}{|c|}{ Normal } & \multicolumn{2}{|c|}{ NIHL } & \multicolumn{2}{|c|}{ Others } \\
\hline & $n$ & $\%$ & $n$ & $\%$ & $n$ & $\%$ & $n$ & $\%$ & $n$ & $\%$ & $n$ & $\%$ \\
\hline NG & 33 & 78.57 & 7 & 16.66 & 2 & 4.76 & 29 & 69.04 & 7 & 16.66 & 6 & 14.28 \\
\hline NSG & 47 & 82.45 & 3 & 5.26 & 7 & 12.28 & 46 & 80.70 & 3 & 5.26 & 8 & 14.03 \\
\hline
\end{tabular}

Abbreviations: NG, noise group; NSG, noise and solvent group; NIHL, noise-induced hearing loss. 
Table 3 Averages of hearing thresholds of groups according to gender ( $n=198$ )

\begin{tabular}{|c|c|c|c|c|c|c|c|c|}
\hline \multirow{3}{*}{$\begin{array}{l}\text { Ears and } \\
\text { frequencies }(\mathrm{kHz})\end{array}$} & \multicolumn{8}{|c|}{ Threshold averages-groups and gender $(n)$} \\
\hline & \multicolumn{2}{|c|}{ NG } & \multicolumn{2}{|c|}{$\mathrm{CN}$} & \multicolumn{2}{|c|}{ NSG } & \multicolumn{2}{|c|}{ CNS } \\
\hline & $\begin{array}{l}M \\
(n=30)\end{array}$ & $\begin{array}{l}F \\
(n=12)\end{array}$ & $\begin{array}{l}M \\
(n=30)\end{array}$ & $\begin{array}{l}F \\
(n=12)\end{array}$ & $\begin{array}{l}M \\
(n=37)\end{array}$ & $\begin{array}{l}\mathrm{F} \\
(n=20)\end{array}$ & $\begin{array}{l}M \\
(n=37)\end{array}$ & $\begin{array}{l}F \\
(n=20)\end{array}$ \\
\hline RE 0.5 & 11.8 & 10.4 & 8.7 & 9.6 & 12.4 & 11.3 & 8.1 & 9.5 \\
\hline RE 1 & 11.7 & 8.3 & 8.5 & 7.1 & 12.3 & 11.3 & 8.9 & 7.5 \\
\hline RE 2 & 10.2 & 9.6 & 8.2 & 7.1 & 12.4 & 10.8 & 8.0 & 6.8 \\
\hline RE 3 & 17.2 & 8.8 & 10.5 & 6.7 & 15.8 & 9.5 & 9.3 & 5.3 \\
\hline RE 4 & $23.2^{\mathrm{a}}$ & 10.4 & 12.5 & 10.4 & 19.2 & 11.8 & 11.9 & 8.8 \\
\hline RE 6 & 22.8 & 15.8 & 13.3 & 15.0 & 20.7 & 17.0 & 13.4 & 13.3 \\
\hline RE 8 & 18.5 & 14.2 & 14.3 & 14.2 & 18.2 & 16.3 & 13.1 & 8.3 \\
\hline LE 0.5 & 10.3 & 8.6 & 8.3 & 10.0 & 13.5 & 12.0 & 8.1 & 8.0 \\
\hline LE 1 & 10.2 & 15.8 & 9.5 & 7.1 & 12.3 & 11.8 & 8.6 & 6.5 \\
\hline LE 2 & 11.8 & 15.4 & 9.7 & 5.8 & 13.9 & 10.3 & 8.4 & 6.0 \\
\hline LE 3 & 18.2 & 16.3 & 10.3 & 5.8 & 17.4 & 11.0 & 9.9 & 5.5 \\
\hline LE 4 & $26.2^{\mathrm{a}}$ & 17.1 & 12.3 & 7.9 & 22.0 & 13.5 & 12.3 & 6.8 \\
\hline LE 6 & $27.2^{\mathrm{a}}$ & 12.3 & 13.0 & 12.1 & 22.8 & 16.8 & 11.8 & 10.8 \\
\hline LE 8 & 22.5 & 12.3 & 13.7 & 10.0 & 20.5 & 14.8 & 14.6 & 8.3 \\
\hline
\end{tabular}

Abbreviations: CN, control noise group; CNS, control noise and solvent group; LE, left ear; NG, noise group; NSG, noise and solvent group; RE, right ear. a Statistically significant $(p<0.05)$, Mann-Whitney test.

Importantly, in the group exposed to noise and solvents simultaneously, worsening thresholds occurred not only at high frequencies but also at low frequencies (-Table 4), which indicates that simultaneous exposure results in sequelae in different regions of the cochlea. ${ }^{16}$ In contrast, exposure to noise only left sequelae only at high frequencies ( - Table 4), confirming data reported in Appendix I of NR-7. 24

Table 4 Comparing hearing thresholds of the four groups according to gender $(n=198)$

\begin{tabular}{|c|c|c|c|c|}
\hline \multirow[t]{3}{*}{ Ears and frequencies $(\mathrm{kHz})$} & \multicolumn{4}{|c|}{ p compared across groups } \\
\hline & \multicolumn{2}{|c|}{$\mathrm{NG}$ and $\mathrm{CN}$} & \multicolumn{2}{|c|}{ NSG and CNS } \\
\hline & Male & Female & Male & Female \\
\hline RE 0.5 & 0.0586 & 0.7373 & 0.2591 & $0.0015^{a}$ \\
\hline RE 1 & 0.1342 & 0.6925 & $0.0423^{a}$ & 0.3017 \\
\hline RE 2 & 0.2625 & 0.2437 & 0.1031 & 0.1747 \\
\hline RE 3 & 0.1678 & 0.4951 & $0.0208^{a}$ & $0.0426^{a}$ \\
\hline RE 4 & $0.0112^{\mathrm{a}}$ & 0.6153 & 0.2027 & $0.0143^{a}$ \\
\hline RE 6 & $0.0053^{\mathrm{a}}$ & 0.2632 & 0.1776 & 0.1218 \\
\hline RE 8 & 0.3536 & 0.7012 & $0.0191^{\mathrm{a}}$ & 0.3306 \\
\hline LE 0.5 & 0.3216 & 0.3586 & $0.0268^{a}$ & $0.0052^{a}$ \\
\hline LE 1 & 0.7619 & 0.3805 & $0.0271^{a}$ & 0.3170 \\
\hline LE 2 & 0.9625 & 0.3734 & 0.0517 & 0.1394 \\
\hline LE 3 & 0.0750 & 0.2444 & $0.0406^{\mathrm{a}}$ & 0.0689 \\
\hline LE 4 & $0.0017^{a}$ & 0.4860 & $0.0231^{a}$ & $0.0073^{a}$ \\
\hline LE 6 & $0.0003^{a}$ & 0.9745 & $0.0119^{a}$ & $0.0004^{a}$ \\
\hline LE 8 & $0.0338^{a}$ & 0.5007 & $0.0112^{\mathrm{a}}$ & 0.3961 \\
\hline
\end{tabular}

Abbreviations: CN, control noise group; CNS, control noise and solvent group; LE, left ear; NG, noise group; NSG, noise and solvent group; RE, right ear. a Statistically significant $(p<0.05)$, Mann-Whitney test. 
Table 5 Comparison of the groups according to age group $(n=198)$

\begin{tabular}{|l|l|l|l|l|l|l|l|l|}
\hline \multirow{2}{*}{$\begin{array}{l}\text { Ears and } \\
\text { frequencies (kHz) }\end{array}$} & \multicolumn{9}{|c|}{ Age group (y) } \\
\cline { 2 - 9 } & \multicolumn{2}{|c|}{ Under 30 } & \multicolumn{2}{c|}{$30-39$} & \multicolumn{2}{c|}{ 40-49 } & \multicolumn{2}{c|}{50 and over } \\
\cline { 2 - 9 } & NG $\times$ CN & NSG $\times$ CNS & NG $\times$ CN & NSG $\times$ CNS & NG $\times$ CN & NSG $\times$ CNS & NG $\times$ CN & NSG $\times$ CNS \\
\hline RE 0.5 & $0.0241^{\mathrm{a}}$ & 0.1553 & 0.1386 & 0.3503 & 0.0807 & $0.0010^{\mathrm{a}}$ & 0.1074 & 0.7820 \\
\hline RE 1 & $0.0205^{\mathrm{a}}$ & 0.7966 & 0.2331 & 0.5704 & 0.0862 & $0.0043^{\mathrm{a}} \mathrm{h}$ & 0.5965 & 0.8378 \\
\hline RE 2 & $0.0477^{\mathrm{a}}$ & 0.7142 & 0.5059 & 0.1781 & 0.0890 & $0.0028^{\mathrm{a}}$ & 0.6927 & 0.1284 \\
\hline RE 3 & $0.0262^{\mathrm{a}}$ & 0.5505 & $0.0471^{\mathrm{a}}$ & 0.1194 & 0.0631 & $0.0008^{\mathrm{a}}$ & 0.2165 & 0.1715 \\
\hline RE 4 & 0.2500 & 0.8823 & 0.3769 & 0.4321 & $0.0015^{\mathrm{a}}$ & $0.0005^{\mathrm{a}}$ & 0.2191 & 0.9481 \\
\hline RE 6 & 0.1141 & 0.8039 & 0.6168 & 0.1482 & $0.0011^{\mathrm{a}}$ & $0.0442^{\mathrm{a}}$ & 0.3347 & 0.6708 \\
\hline RE 8 & 0.0673 & 0.6244 & 0.3104 & 0.0617 & 0.2990 & $0.0147^{\mathrm{a}}$ & 0.7968 & 0.5183 \\
\hline LE 0.5 & 0.5037 & 0.3720 & 0.1539 & 0.0583 & 0.1450 & $0.0042^{\mathrm{a}}$ & 0.5117 & 0.3191 \\
\hline LE 1 & 0.5761 & 0.3175 & 0.4967 & 0.2645 & 0.8581 & 0.0532 & 0.3609 & 0.9470 \\
\hline LE 2 & 0.3429 & 0.6537 & 0.1236 & 0.3588 & 0.2495 & $0.0070^{\mathrm{a}}$ & 0.3658 & 1.0000 \\
\hline LE 3 & 0.0510 & 0.4189 & 0.2670 & 0.9057 & $0.0116^{\mathrm{a}}$ & $0.0012^{\mathrm{a}}$ & 0.3668 & 0.4773 \\
\hline LE 4 & 0.0629 & 0.4334 & 0.6114 & 0.2610 & $0.0010^{\mathrm{a}}$ & $0.0002^{\mathrm{a}}$ & $0.0464^{\mathrm{a}}$ & 0.3994 \\
\hline LE 6 & 0.1242 & 0.1554 & 0.1694 & $0.0028^{\mathrm{a}}$ & $0.0021^{\mathrm{a}}$ & $0.0010^{*}$ & 0.0981 & 0.6493 \\
\hline LE 8 & 0.2544 & 0.9222 & 0.4853 & 0.0724 & 0.0647 & $0.0391^{*}$ & 0.1961 & 0.9483 \\
\hline
\end{tabular}

Abbreviations: CN, control noise group; CNS, control noise and solvent group; LE, left ear; NG, noise group; NSG, noise and solvent group; RE, right ear. ${ }^{a}$ Statistically significant $(p<0.05)$, Mann-Whitney test.

In - Table 5, comparing the hearing thresholds with age, there was a statistically significant difference between the thresholds of the NSG in relation to CNS in participants ages 40 to 49 , in accordance with the literature. ${ }^{28-30}$

During the research we found some limitations: (1) access only to the last regular audiometry exam and (2) access only to biological concentration (hippuric acid and methyl hippuric) of 19 subjects in the NSG, which ranged from 0.02 to $0.667 \mathrm{~g} / \mathrm{g}$ of creatinine (hippuric acid) and from 0.001 to $0.58 \mathrm{~g} / \mathrm{g}$ of creatinine (methyl hippuric acid). These limitations do not allow identification of hearing losses (onset or worsening of noise-induced hearing loss) and the realization of associations between audiological findings and solvent concentration.

To prevent hearing loss in workers exposed to noise and solvents, the inclusion of this population in Hearing Conservation Programs is recommended, even when the concentration of solvents and noise levels are below or within the limits of tolerance, because the combined effect may be additive.

\section{Conclusion}

Exposure to noise and solvents poses a risk to hearing. Females showed less susceptibility to noise than the males at frequencies of $4 \mathrm{kHz}$ and $6 \mathrm{kHz}$; however, when exposed to solvents, female hearing was affected similarly to male hearing. The 40- to 49-year age group showed significant worsening in hearing thresholds of the NSG compared with CNS. The ongoing research on this issue is essential because there is strong evidence that hearing loss can be caused not only by noise but also by exposure to solvents or other environmental contaminants. ${ }^{20,21}$ Also recommended are new studies related to combined exposure by gender.

\section{References}

1 NIOSH-National Institute for Occupational Safety and Health. Preventing occupational hearing loss-a practical guide. Pub. No. 96-110. Washington, DC: U.S. Department of Health and Human Services; 1996

2 Lacerda ABM, Morata TC. O risco de perda auditiva decorrente da exposição ao ruído associada a agentes químicos. In: Morata TC, Zucki F, ed. Saúde Auditiva-Avaliação de Riscos e Prevenção. São Paulo, Brazil: Plexus; 2010:99-117

3 Morata TC, Little MB. Suggested guidelines for studying the combined effects os occupational exposure to noise and chemicals on hearing. Noise Health 2002;14(4):73-87

4 Werner AF. Afecciones auditivas de origem ocupacional: de la prevención a la rehabilitación. Buenos Aires, Brazil: Ed. Dosyuna; 2006

5 Morata TC. Promoting hearing health and the combined risk of noise-induced hearing loss and ototoxicity. Audiol Med 2007; 5:33-40

6 Fuente A, Slade MD, Taylor T, et al. Peripheral and central auditory dysfunction induced by occupational exposure to organic solvents. J Occup Environ Med 2009;51(10):1202-1211

7 Aylott S, Prasher D. Solvents impair balance in man. Noise Health 2002;4(14):63-71

8 Sliwinska-Kowalska M, Zamyslowska-Szmytke E, Szymczak W, et al. Effects of coexposure to noise and mixture of organic solvents on hearing in dockyard workers. J Occup Environ Med 2004;46(1): 30-38

9 Kim J, Park H, Ha E, Jung T, Paik N, Yang S. Combined effects of noise and mixed solvents exposure on hearing function among workers in the aviation industry. Ind Health 2005;43(3): 567-73 
10 Fuente A, McPherson B. Organic solvents and hearing loss: the challenge for audiology. Int J Audiol 2006;45(7):367-381

11 Fuente A, McPherson B, Muñoz V, Pablo Espina J. Assessment of central auditory processing in a group of workers exposed to solvents. Acta Otolaryngol 2006;126(11):1188-1194

12 Volpin A, Saia B. Interazione tra solventi e rumore: stato dell'arte. G Ital Med Lav Ergon 2006;28(1):20-24

13 Botelho CT, Paz APML, Gonçalves AM, Frota S. Comparative study of audiometrics tests on metallurgical workers exposed to noise only as well as noise associated to the handling of chemical products. Rev Bras Otorrinolaringol 2009;75(1):95-102

14 Mohammadi S, Labbafinejad Y, Attarchi M. Combined effects of ototoxic solvents and noise on hearing in automobile plant workers in Iran. Arh Hig Rada Toksikol 2010;61(3):267-274

15 Rizk SA, Sharaf NE. Health hazards among a sample of workers exposed to a combination of noise and organic solvents in a fermentation factory in Egypt. Nature Sci 2010;8(6):95-99

16 Sliwinska-Kowalska M, Zamyslowska-Szmytke E, Szymczak W, et al. Hearing loss among workers exposed to moderate concentrations of solvents. Scand J Work Environ Health 2001;27(5): 335-342

17 Morata TC, Dunn DE, Kretschmer LW, Lemasters GK, Keith RW. Effects of occupational exposure to organic solvents and noise on hearing. Scand J Work Environ Health 1993;19(4):245-254

18 Chang SJ, Chen CJ, Lien CH, Sung FC. Hearing loss in workers exposed to toluene and noise. Environ Health Perspect 2006; 114(8):1283-1286

19 Morata TC. Interaction between noise and asphyxiants: a concern for toxicology and occupational health. Toxicol Sci 2002;66(1):1-3

20 Fuente A, McPherson B. Central auditory processing effects induced by solvent exposure. Int J Occup Med Environ Health 2007; 20(3):271-279
21 Fuente A, McPherson B. Central auditory damage induced by solvent exposure. Int J Occup Saf Ergon 2007;13(4):391-397

22 Brasil. Normas regulamentadoras $n^{\circ} 15$. Atividades e Operações Insalubres. In: Segurança e Medicina do Trabalho. $56^{\circ}$ ed. São Paulo, Brazil: Atlas; 2005

23 Vieira S, Hossne WS. Metodologia Científica para a Área da Saúde. Rio de Janeiro, Brazil: Ed. Campus; 2001

24 Brasil. Ministério do Trabalho. Secretaria de Saúde e Segurança no Trabalho Portaria No. 19, de 9 de abril de 1998. Estabelece diretrizes e parâmetros mínimos para avaliação e acompanhamento da audição em trabalhadores expostos a níveis de pressão sonora elevados. Diário Oficial da República Federativa do Brasil, Brasília (DF); 1998(Abr 9; Seção I):64-6

25 Brasil. Norma Regulamentadora $n^{\circ}$ 9-Programa de Prevenção de Riscos Ambientais. In: Segurança e Medicina do Trabalho. $56^{\circ}$ ed. São Paulo, Brazil: Atlas; 2005

26 American Conference of Governmental Industrial HygienistsACGIH. Threshold Limit Values for Chemical Substances and Physical Agents and Biological Exposure Indices 1998-1999. Cincinnati, OH: ACGIH; 1999

27 Brasil. Ministério da Previdência e Assistência Social. Decreto n 3048, 12 maio 1999

28 Gates GA, Cooper JC Jr, Kannel WB, Miller NJ. Hearing in the elderly: the Framingham cohort, 1983-1985. Part I. Basic audiometric test results. Ear Hear 1990;11(4):247-256

29 Pearson JD, Morrell CH, Gordon-Salant S, et al. Gender differences in a longitudinal study of age-associated hearing loss. J Acoust Soc Am 1995;97(2):1196-1205

30 Pinto NMC. Alternativa para análise longitudinal de resultados audiométricos. In: Morata TC, Zucki F, eds. Caminhos para saúde Auditiva-Ambiental-Ocupacional. São Paulo, Brazil: Plexus; 2005:173-188 